\title{
Profissão Professor: a dimensão afetiva contemplada em sua identidade $^{1}$
}

\author{
Rebeca Possobom Arnosti \\ Universidade Estadual Paulista "Júlio de Mesquita Filho", Rio Claro, SP-Brasil. \\ rebk_pa@hotmail.com \\ Larissa Cerignoni Benites \\ Universidade Estadual Paulista "Júlio de Mesquita Filho", Rio Claro, SP - Brasil. \\ Ibenites@rc.unesp.br \\ Samuel de Souza Neto \\ Universidade Estadual Paulista "Júlio de Mesquita Filho", Rio Claro, SP - Brasil. \\ samuelsn@rc.unesp.br
}

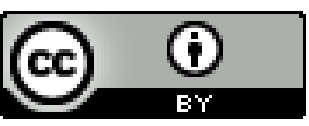

Educação: teoria e prática, Rio Claro, SP, Brasil - elSSN: 1981-8106

Está licenciada sob Licença Creative Common

\section{Resumo}

A pesquisa emerge do cenário de crises e contradições que envolvem a educação, os professores e a sua identidade. Na tentativa de desvelar a identidade, visando encontrar elementos que contribuam com a construção da profissionalidade docente, partiu-se da importância em se investir no desenvolvimento pessoal do professor, contemplando sua dimensão afetiva. O objetivo foi identificar, a partir de depoimentos e práticas de docentes, os aspectos constitutivos da dimensão (sócio)afetiva de sua identidade. Trata-se de uma pesquisa qualitativa, tendo como instrumentos de coleta de dados observações e entrevistas semiestruturadas. Os dados contemplam as diferentes categorias da profissionalidade docente, sendo que se visualiza como a afetividade assume papel essencial na formação e no trabalho dos professores, pois seu desenvolvimento possibilita a construção de uma prática pedagógica diferenciada, facilita a elaboração de trabalhos pedagógicos coletivos e,

\footnotetext{
${ }^{1}$ Apoio: CNPq
} 
ainda, quando reconhecida e desenvolvida na graduação, contribui para que crenças e princípios pessoais sejam reavaliados sob uma perspectiva científica e profissional.

Palavras-chave: Dimensão Afetiva. Identidade Docente. Profissionalidade Docente.

\title{
Teacher Profession: the affective dimension contemplated in identity
}

\begin{abstract}
The research emerges from the scene of crises and contradictions involving education, the teachers and their identity. In an attempt to unveiling this identity in order to find elements that contribute to the construction of the teaching profession, we started with the assumption of the importance of investing in personal development teacher, contemplating their affection. The objective was to identify as from speech and practice's teachers the constituent aspects of the dimension (socio-)affective identity of the teachers. This is a qualitative research, as instruments of data collection observations and semi structured interviews. The information include different categories of professional teaching, so that you can visualize how the affection assumes keys role in the formations and work of teachers, since their development enables the construction of the differentiated pedagogical practice, facilitating the elaboration of pedagogical collective and even when recognized and developed in undergraduate, contributes to personal beliefs and principles may be reassessed under a scientific perspective and professional.
\end{abstract}

Keywords: Affective dimension. Teacher Identity. Teacher Professionalism.

\section{Introdução}

Este artigo se insere na temática sobre formação de professores, partindo do ponto de vista que existe uma crise, motivada pelas grandes transformações e contradições do século XXI, que atinge a realidade educacional e a identidade dos professores.

Crise que não abrange apenas as características profissionais, mas remete, inclusive, à dimensão pessoal, pois "os momentos de balanço retrospectivo sobre os percursos pessoais e profissionais são momentos em que cada um produz a "sua vida", o que no caso dos professores é também produzir a "sua" profissão" (NÓVOA, 1992, p. 26, grifos do autor).

Nesse sentido, este trabalho privilegia o desenvolvimento pessoal, principalmente no que se refere à dimensão afetiva, considerando afetividade como um termo polissêmico, e relacionado ao cuidado,ajuda, sentimento de apego, ternura, empatia, afeto, amizade, amor e carinho (AMADO et al, 2009, p.77). Apesar da complexidade e ambiguidade que envolvem o termo, este estudo compartilha das ideias propostas por esses autores, priorizando:

[...] os sentidos que apontam para atitudes de respeito, de empatia, de abertura ao outro, e que se prendem com sentimentos (bem estar 
subjetivo) e emoções (alegria, satisfação, confiança, sentimento de si), decorrentes de situações e contextos de interacção pedagógica em que aquelas atitudes prevalecem.

Pensando nas emoções, entende-se que essas constituem o processo de socialização, sendo que, através delas, a pessoa entra em contato com seu interior e com o mundo que a cerca, relaciona-se com ela mesma e com o outro. E é neste sentido que enxergamos que pela afetividade perpassa o princípio - ou a tentativa - de se colocar no lugar do outro; de caminhar segundo a alteridade, entendendo que é o "outro" que contribui com meu desenvolvimento, entendendo que é preciso ir ao encontro do "outro".

Tardif e Lessard (2005) dizem que as interações do ser humano com seu próprio eu e com o mundo subsidiam o trabalho docente. Assim, acredita-se que a afetividade ocupe espaço central nas interações humanas, tendo como objetivo, neste estudo, perceber como a dimensão (sócio)afetiva constitui a identidade dos professores, a partir da prática e do discurso de seis professoras do Ensino Fundamental.

\section{$2 \quad$ Metodologia}

A pesquisa baseou-se na abordagem qualitativa, pautando-se no construtivismo social, no qual o pesquisador procura compreender os significados atribuídos pelos sujeitos às experiências e acontecimentos dos quais participaram, buscando apreender a cultura de um grupo ou organização, dentro da qual coexistem divergentes visões (ALVES-MAZZOTTI; GEWANDSZNADJDER, 2002).

Quanto às técnicas, optou-se pelas observações e entrevistas semiestruturadas. Os dados foram sistematizados por meio da análise de conteúdo (BARDIN, 1979). A escolha se deve ao fato de a tal análise buscar apreender aquilo que está por trás das palavras, bem como outras realidades e mensagens. As principais etapas da análise foram: operacionalização das ideias; significados atribuídos aos dados brutos (codificação) e classificação dos elementos (categorização). 
Esta pesquisa foi aprovada pelo Comitê de Ética da instituição (Protocolo 3330, decisão 063/2011) e todas as participantes assinaram o termo de consentimento livre e esclarecido.

O contato com as professoras deu-se de maneira aleatória. Todas trabalhavam em escolas de um município do interior paulista, e aceitaram participar das observações e entrevistas. Cinco delas atuavam em uma escola privada de tempo integral e uma na rede pública de ensino. Cada professora foi observada por aproximadamente 20 horas, entre março e agosto de 2011.

A Professora K atuava no primeiro ano; a Professora F no segundo; as Professoras C e E no quarto e as Professoras $Q$ e R no quinto ano. Todas cursaram Magistério e Pedagogia, com exceção da Professora K, que só fez Pedagogia. As Professoras C, K e R têm especialização. Quanto à experiência profissional, as docentes possuem entre 10 e 25 anos de tempo de carreira.

\section{Cenário Educacional: transformações que perpassam profissão e identidade docente}

A escola pública brasileira é marcada pelas inúmeras mudanças que ocorreram ao longo dos séculos, não apenas no campo educacional, mas, também, no meio político, social e econômico, sendo que esse contexto mais amplo não deixa de influenciar a profissão docente, de modo que:

[...] nos últimos cinquenta anos, graças às transformações de diversa natureza que se verificaram nas sociedades industrializadas e estiveram na origem da globalização e da sociedade da informação, a profissão se foi tornando crescentemente complexa. E talvez nunca o fosse tanto como está a ser nos nossos dias, visto que hoje se pede tudo à escola e aos professores, mesmo aquilo que dificilmente poderão dar (ESTRELA, 2010, p. 06).

Maués (2003) corrobora com a autora, pois também acredita que, com o desenvolvimento do capitalismo e do livre mercado, a educação sofreu diversas influências, passando a ser vista como mercadoria. Já a globalização necessita da expansão dos 
mercados, para isso é preciso que o Estado seja desregulamentado, enquanto as políticas neoliberais pretendem extinguir as barreiras administrativas ou políticas, estimulando a entrada de capitais internacionais, prezando pela eficácia econômica. Desse modo, a Educação consiste em um meio para abranger tais finalidades.

Pode-se identificar a busca pela eficiência no processo educacional - como nas empresas, procura-se fazer mais gastando menos -, estabelecendo aí uma estratégia competitiva, focando nos resultados e rankeamentos das instituições (ENGUITA, 1996). Assim, as políticas neoliberais acentuam o individualismo e a competição, prejudicando a solidariedade coletiva e reforçando um processo antidemocrático de seleção natural, onde os melhores alcançam bens maiores e os mais frágeis sucumbem (GENTILI, 1996).

Em meio às contradições que envolvem a pós-modernidade e contribuem para a emergência de uma crise na educação, Esteve (1992) pontua doze aspectos básicos que ocasionaram mudanças no sistema educacional, especificamente no trabalho do professor, entre os quais estão: menor valorização docente; aumento das exigências em relação ao professor; inibição de outros agentes de socialização (com a entrada assídua dos membros familiares no mercado de trabalho, a família reduziu sua atenção às crianças); desenvolvimento de fontes de informação alternativas à escola; ruptura do consenso social sobre a educação (se antes a educação convergia para a cultura dominante, agora é preciso aceitar a diversidade presente na sala de aula); a modificação do apoio da sociedade ao sistema educativo (a massificação do ensino não garantiu a ascensão social aos menos favorecidos, levando a sociedade a abandonar a ideia de educação como promessa de um futuro melhor).

A docência ainda enfrenta um processo de desprofissionalização, sendo considerada uma semiprofissão ou ofício (PAPI, 2005; CONTRERAS, 2002), já que parece não atender à maioria dos requisitos de formação e organização que uma profissão deve cumprir, como exigir alto grau de destreza dos sujeitos que nela atuam; requerer um corpo de conhecimentos sistemáticos que ofereçam subsídios à experiência prática; exigir que a formação propicie a socialização dos valores profissionais, os quais devem estar explícitos em um código de ética (HOYLE, 1980). Isso acaba por gerar aquilo que Nóvoa (1992) 
chamou de proletarização da docência, na qual, em linhas gerais, se tem a perda da autonomia e produção do trabalho.

Para Enguita (1991), quando esse processo se dá de uma maneira contínua e prolongada, resulta em uma perda de controle da classe e da organização de suas atividades, abrangendo "[...] efeitos permanentes, de caráter negativo, que afetam a personalidade do professor, como resultado das condições psicológicas e sociais em que exerce a docência, devido à mudança social acelerada" (ESTEVE, 1992, p. 98).

Lüdke e Boing (2004) comentam que a precarização do trabalho docente repercute sobre a construção da identidade dos professores, compreendendo-a como uma construção histórico-social que perpassa o processo de socialização, as experiências e vivências, pessoais e profissionais. Sendo assim, neste estudo, considerou-se que a identidade profissional é "[...] uma construção marcada por múltiplos fatores que interagem entre si, resultando numa série de representações que os docentes fazem de si mesmos e de suas funções [...]" (GARCIA; HYPÓLITO; VIEIRA, 2005, p. 54-55).

Contreras (2002) também caminha em prol dessa construção identitária e busca por elementos que favoreçam a profissionalização da docência, sendo essencial que os professores desenvolvam a sua profissionalidade, compreendendo-a em três categorias: (1) Obrigação moral - o professor encontra-se comprometido com o desenvolvimento dos alunos como pessoas; o ensino é um trabalho moral porque se atua numa relação desigual com os alunos, mas acreditando que tal desigualdade será usada para promover o desenvolvimento de capacidades que os tornem independentes. (2) Compromisso com a Comunidade - educar não é um problema da vida particular dos professores, mas trata-se de uma ocupação socialmente encomendada e responsabilizada publicamente. (3) Competência Profissional - para obter um desempenho satisfatório o profissional deve ser competente para tal; a categoria remete à competência técnica e ao conjunto de saberes necessários ao exercício da profissão, enquanto prática social.

Interessante notar que as categorias não remetem apenas ao caráter técnico da profissão, porém referem-se a uma dimensão pessoal, indicam que os docentes devam estabelecer uma relação de comprometimento com o trabalho, responsabilizando-se pelo desenvolvimento dos educandos e esforçando-se para exercer um trabalho construído 
coletivamente, trocando experiências comos pares e considerando as expectativas da comunidade.

\section{Dimensão Afetiva: suas contribuições à profissionalidade docente}

As mudanças sociais, políticas e econômicas que afetam o trabalho docente delinearam a primeira parte deste estudo. A identidade profissional emergiu nesse processo, na tentativa de se verificar quais as consequências sobre ela mediante a tantas transformações. Dessa forma, busca-se compreender como profissionalidade, identidade e afetividade podem se complementar. Se a afetividade se dá por meio das interações, cabe conjeturar de que maneira essas se constroem ao longo do desenvolvimento enquanto pessoa e, por assim dizer, enquanto professores.

Amado et al. (2009) ajudaram a entender a afetividade como algo relacionado ao respeito e à abertura que se dá ao outro, o que pode promover sentimentos e emoções positivas, como bem-estar, alegria, confiança, sentimento de si. Souza Neto e Hunger (2002) dizem que pela dimensão afetiva devam perpassar elementos como o respeito e a alteridade; estando a alteridade vinculada à ideia de não pensar no outro como estranho ou inimigo, mas como alguém que nos completa, contribui com nosso amadurecimento e nos mostra que não somos capazes de fazer nada sozinhos.

Neste caminho, a dimensão afetiva nos leva a pensar nas interações que se estabelecem com o outro. Interações que são essenciais à constituição da personalidade, da identidade, sendo estabelecidas desde a socialização primária, a partir dos primeiros contatos com os familiares mais íntimos (GRIGOROWITSCHS, 2008) e tornando-se mais complexas na medida em que o ser humano inicia os processos de socialização secundária, ampliando cada vez mais a quantidade de ambientes e pessoas com os quais interage. Logo, existe a interação consigo, com o outro e com o contexto em que se insere.

Baseando-se nesses três tipos de interações humanas, visa-se remeter à docência, percebendo como a dimensão afetiva pode constituir a identidade e a prática dos educadores. Por esse viés, a profissionalidade docente contribui com este estudo (CONTRERAS, 2002). 
A perspectiva da obrigação moral foi ao encontro de todas as professoras entrevistadas, que reconheceram que a docência extrapola o ensino dos conteúdos, abrangendo questões afetivas, morais e éticas, que abarcam a relação com os alunos.

As professoras $\mathrm{Q}$ e $\mathrm{K}$ destacaram o fato de seus alunos estudarem em período integral, afirmando ter maior preocupação com a dimensão afetiva em função disso. Essa questão parece influenciar sua identidade, uma vez que as docentes se sentem no dever de assumir novas funções:

Eu acho que com os pequenininhos a gente tem uma relação bem mais próxima. E também tem a questão de ficar o dia todo. [...] Na escola eles passam nove horas. Comigo oito horas. Então eu estava até refletindo sobre isso, eu não sou só professora deles, eu sou uma segunda mãe deles. Eu não tenho que dar conta só da grade curricular, eu tenho que dar conta da educação, dos valores (PROFESSORA K).

Conforme demonstrou Esteve (1992), a redução do apoio dos pais aos filhos em relação aos estudos é uma característica do século XX que pode acarretar mudanças na identidade docente. Cunha (1996) mostra como esse processo começou a ocorrer no Brasil, sendo que se tem a ideia de que a educação dos filhos não é de responsabilidade única de seus pais. Por um lado, os filhos precisam ficar na escola enquanto seus pais saem para trabalhar; por outro lado, há a ideia de que crianças e jovens devam passar longo tempo em espaços educativos, investindo em sua formação para, futuramente, exercer uma excelente profissão.

Essa questão aparece como central nas preocupações das professoras $Q$ e K, e também de $\mathrm{R}$, ao referendar que tal situação pode gerar certos problemas, já que os valores ou o modo de ensinar do professor nem sempre coincidem com as expectativas da família. Nota-se aí outra mudança social que parece afetar a profissão docente: a falta de apoio dos pais à figura do professor (ESTEVE, 1992):

Mas para mim, entendo que afetividade não é só passar a mão na cabeça, afetividade é por limites. [...] Aí o educador vai além dos conteúdos, mas muitas vezes nem a família concorda (PROFESSORA R); [...] Tive um caso de um aluno que chamei a mãe, a mãe me tratou super mal, falou que eu estava com implicância com o filho dela, porque eu a chamei pra pedir 
ajuda. Vi que o menino tem problema, e a mãe não aceita, então a culpada é a professora [...]" (PROFESSORA K).

Contudo, todas as professoras reconhecem que a dimensão afetiva faz parte das relações vividas em sala de aula, e que por meio da mesma estabelecem vínculos com os alunos. Porém, as observações mostraram que nem todas lidam com essa dimensão da mesma forma. Quatro docentes (R, K, E, F) assumem tal preocupação, aproximando-se do Modelo de Educação como Molde, no qual: "[...] a geração adulta tem o direito natural de definir as metas, os objetivos e os conceitos básicos que devem ser assimilados pelas gerações jovens" (ESTEVE, 2004, p. 96).

Já duas docentes ( $Q$ e $C$ ) apresentam posturas e discursos diferenciados, pois não dizem ou impõem aos alunos o que gostariam que eles fizessem, ou quais atitudes são as mais corretas. Realizam um trabalho baseado, principalmente, no diálogo, promovendo a reflexão, a criticidade e a autonomia ${ }^{2}$ dos educandos.

Nas aulas, a Professora $Q$ propõe a atividade e deixa um tempo livre para que as próprias crianças organizem seus grupos, montem seus textos e conversem sobre como farão o que foi solicitado. Ela apresenta os objetivos com clareza, mas abre espaço para que seus alunos os realizem de acordo com o ritmo e a maneira que melhor lhes convém. A educadora também conversa constantemente com as crianças. Na entrevista, ela nos disse que considera importante que todos aprendam a falar e a ouvir, buscando compreender as ações e os discursos realizados pelo outro. Seu modo de guiar a sala auxilia na união e na organização do grupo. Os alunos destacam-se pela sua capacidade de sentar, parar para conversar e assim buscar soluções para determinado problema. Mais interessante ainda é perceber que eles continuam a assumir tais posturas quando a professora precisa se ausentar.

\footnotetext{
${ }^{2}$ Entende-se aqui que "na autonomia, as regras são bastante legitimadas pelos sujeitos porque estes se tornam responsáveis pelo contrato que estabeleceram. São obedientes, portanto, mas não cegamente, porque acreditam na necessidade de que as regras sirvam para o bem de cada um e de todos os possíveis contratantes" (TOGNETTA; ASSIS, 2006, p. 52).
} 
A Professora C também preza pela relação entre os alunos e o cuidado com o outro, sempre enfatiza que as crianças devem colocar-se no lugar do outro. Ela baseia suas repreensões e ensinamentos na prática do diálogo. Os alunos parecem fazer questão de se expressar, pois sabem que são ouvidos com atenção por todos do grupo.

Uma de suas aulas foi dedicada a problemas que estavam acontecendo com o Aluno $\mathrm{S}$, pois este vinha irritando constantemente os colegas e atrapalhando o trabalho da classe. Uma roda foi feita e um diálogo foi estabelecido com toda a turma, cada um pôde se colocar, demonstrando porque o Aluno S o incomodava. O Aluno S, por sua vez, pôde se explicar. O ápice da cena foi quando a Professora C, corajosamente, disse a seus alunos: "Por favor, para terminar, ergam a mão aqueles que gostam do que o Aluno S vem fazendo nesta semana". Silêncio total. Ninguém ergueu a mão. Em seguida, a Professora C completou: "Agora, por favor, ergam a mão aqueles que gostam do Aluno S". Num silêncio respeitoso, vimos trinta crianças - todos os presentes - de nove ou dez anos de idade erguendo os braços. Então, a Professora C olhou para o Aluno S e disse: "Está vendo o quanto você é amado? Todos nós gostamos muito de você e estamos aqui para te ajudar a melhorar, para te dar força porque não queremos mais ver você metido nessas confusões...".

Assim, nota-se que os elementos pontuados parecem constituir a identidade das participantes do estudo, pois a forma como se comportam, as atitudes assumidas e mesmo a relação que estabelecem com a docência e com os alunos demonstram uma construção pessoal edificando-se e apontando para o desenvolvimento da dimensão afetiva.

As Professoras $C$ e $Q$ realizam isso de maneira mais profunda, pois a afetividade ocupa o centro de sua prática pedagógica e, assim, assumem a categoria da obrigação moral de forma efetiva, pois mostram-se mais conscientes quanto à dimensão moral que abarca a formação de seus alunos, pensando e avaliando sua atuação profissional de forma a proporcionar um ensino que supere a transmissão de conteúdos, abrangendo uma Educação que se faça por meio de diálogos, debates, confronto de ideias, criticidade e democracia.

Suas aulas não parecem se adequar ao Modelo de Educação como Molde, mas se aproximam, principalmente, do Modelo de Educação como Iniciação, no qual a afetividade ocupa o âmago do processo educacional e constroem-se valores adequados à sociedade 
democrática e pluralista, entendendo que iniciar é abrir as portas para novos conhecimentos e novas realidades, sem nunca estabelecer um final predeterminado, mas oferecendo subsídios para que a pessoa seja capaz de refletir sobre seu contexto com base em suas próprias perspectivas apreendidas (ESTEVE, 2004).

Arendt (2009) também caminha nessa perspectiva, pois entende que os educadores devam assumir um compromisso com a formação das crianças e com a memória histórica e coletiva produzida pela humanidade. A autora não fala apenas sobre a relação que deve ser construída entre docentes e alunos, mas chama a atenção para a interação que o educador deve estabelecer com o mundo, demonstrando que se trata de uma relação, sobretudo, advinda de experiências afetivas:

A educação é o ponto em que decidimos se amamos o mundo o bastante para assumirmos a responsabilidade por ele $e$, com tal gesto, salvá-lo da ruína que seria inevitável não fosse a renovação e a vinda dos novos jovens. A educação é, também, onde decidimos se amamos nossas crianças o bastante para não expulsá-las de nosso mundo e abandoná-las a seus próprios recursos, e tampouco arrancar de suas mãos a oportunidade de empreender alguma coisa nova e imprevista para nós, preparando-as em vez disso com antecedência para a tarefa de renovar um mundo comum (ARENDT, 2009, p. 247, grifo nosso).

Nesse sentido, assumir o compromisso com a tarefa de ensinar vai além da obrigação moral, porque pressupõe, junto a isso, um comprometimento com o mundo e com os contextos em que se vive, zelando por sua durabilidade e por suas heranças simbólicas. Educar implica olhar para o mundo e perceber como ele nos afeta. Perceber de que modo nós o afetamos, para, assim, desenvolver uma relação saudável e amorosa com o meio em que se vive (CARVALHO, 2008).

Pela relação entre docentes e mundo perpassa a categoria do compromisso com a comunidade, entendendo educação como uma ocupação socialmente encomendada e responsabilizada publicamente. $\mathrm{O}$ ato educativo não interessa a um indivíduo, nem a um grupo restrito, mas é necessário para que ahumanidade- nesta relação entre humanos e mundo - prossiga em seu desenvolvimento. 
Assim, o compromisso com a docência vai além do comprometimento com a formação individual de cada aluno, mas pressupõe uma dimensão coletiva, pois tange à questão: Que sociedade pretendemos construir? Em prol desse trabalho coletivo a afetividade emerge, ainda, na troca de experiências e no diálogo que deve existir entre os pares, tornando possível que a escola realize a formação de seus alunos com continuidade, tendo clareza dos valores, das concepções teóricas e das habilidades que as crianças deverão apreender ao longo do processo de escolarização. Freitas (2012) traz a colaboração de autores que demonstram que a educação deve possuir uma essência colaborativa e dependente das interações interpessoais e profissionais que vão sendo construídas no cotidiano escolar:

Nem mesmo a ação didática de um professor se esgota apenas no tempo em que ele passa com o aluno. Afeta outros professores, pois o aluno é o mesmo. Se um deles destrói a autoestima do aluno, todos serão atingidos por este fato (FREITAS, 2012, p. 390, grifo nosso).

Além disso, a relação com os pares também favorece a construção da identidade docente na medida em que a troca de experiências, o compartilhar de dificuldades e êxitos parece ser um fator importante na formação contínua dos professores:

Não se trata de mobilizar a experiência apenas numa dimensão pedagógica, mas também num quadro conceptual de produção de saberes. Por isso, é importante a criação de rede de (auto) formação participada, que permitam compreender a globalidade do sujeito, assumindo a formação como um processo interactivo e dinâmico. A troca de experiências e a partilha de saberes consolidam espaços de formação mútua, nos quais cada professor é chamado a desempenhar, simultaneamente, o papel de formados e de formado (NÓVOA, 1992, p. 26).

Contudo, todas as participantes acreditam que a classe docente tem dificuldades em promover um compromisso com seus pares, indicando que sua classe profissional passa por problemas:

É uma classe sem união, porque se os professores fossem unidos ninguém seguraria. Não se unem por uma causa, esse é um grande problema. Nas escolas também há muitos professores substitutos, o que evita que haja uma estabilidade, dificultando os relacionamentos e a continuidade do trabalho (PROFESSORA E). 
Olha, eu acho que é uma classe um pouco complicada. Porque a gente percebe que as pessoas são muito fechadas, elas não trocam experiências, não trocam informações... [...] Outra característica que também percebo é que as pessoas são muito "engessadas". [...] Outra fala que eu também escuto muito: "O filho não é meu"; "O problema não é meu". Ou então "o problema é meu até dezembro, depois... Vai pra frente!". "Eu ganho pouco, então eu não vou fazer". Quando você escolheu a profissão, você sabia que ganhava pouco (PROFESSORA K).

$\mathrm{Na}$ classe dos professores, assim como qualquer outra classe de trabalhador, tem aquelas pessoas que se interessam muito e tem aquelas pessoas que "levam". Acho que na Educação não deveria haver isso (PROFESSORA C).

Considera-se que os elementos destacados também sejam reflexos das políticas públicas que organizam o trabalho docente, ou mesmo da ausência de algumas medidas que de fato consolidem a docência como profissão, como já apontado anteriormente. Freitas (2012) ressalta que muitas políticas públicas parecem estar equivocadas, pois reforçam o individualismo e a competitividade em vez de estimularem o trabalho coletivo e a colaboração entre os pares, aspectos fundamentais para um contínuo desenvolvimento das escolas e do professor.

O autor verifica que essas políticas públicas incidem sobre o trabalho docente, podendo prejudicar escolas e alunos, mas, também, influenciando a identidade do professor na medida em que este sofre com a desvalorização social, precárias condições de trabalho, falta de espaço para trocar experiências e fomentar novos aprendizados, falta de tempo ou recursos para aprimorar sua formação.

Outro fato que dificulta a existência de um trabalho estruturado de colaboração mútua entre os docentes são as lacunas deixadas pelas Diretrizes Curriculares Nacionais, pois essas não se referem diretamente à dimensão afetiva, ficando a critério de quem as lê interpretar a questão em suas entrelinhas (BRASIL, 2001; BRASIL, 2002).

A dimensão afetiva emergiu em todas as entrevistas, pois todas apontam para algum elemento que esbarra na questão da afetividade e vincula-se a aspectos 
positivos (ex: estabelecer o diálogo e o cuidado com o outro) e negativos (ex: isentar-se da responsabilidade para a formação do outro), revelando que a categoria compromisso com a comunidade não se desenvolve plenamente no trabalho dessas docentes, o qual acaba ficando restrito a práticas isoladas e individualizadas. Somente a Professora E elencou que a afetividade perpassa o seu trabalho, indicando que:

Apesar da classe de docentes não ser unida, aqui na escola não temos esses problemas com os pares, pois a maioria está aqui há muitos anos, são poucos professores substitutos, então os relacionamentos são antigos, todos se conhecem, conversam, trocam ideias, dão risada, falam o que não está bom.

Assim, as relações estabelecidas entre os docentes e seus alunos, entre os próprios docentes e com a comunidade foram apresentadas, sendo que a Educação pode ser considerada:

[...] um elo entre o mundo comum e público e os novos seres que a ele chegam pela natalidade. Nesse sentido, o ensino e o aprendizado justificam-se, não preponderantemente pelo seu caráter funcional ou pela sua aplicação imediata, mas pela sua capacidade formativa" (CARVALHO, 2008, p. 420).

E é em meio a esse processo formativo que se encontra o professor. Acaba sendo essencial que o professor compreenda os elementos que o constituem; sendo capaz de olhar para o que o afeta em sua identidade pessoal e profissional:

O que se tem feito efetivamente para que os professores compreendam, enquanto se educam, a natureza do que é veiculado sobre ensino? Como os cursos de formação têm contribuído para que os indivíduos sejam capazes de pensar sobre a sua própria experiência, explicitar as razões de suas próprias escolhas, ou, ainda, serem capazes de lançar um olhar mais arguto à sua volta, suspeitando dos caminhos já abertos?(CATANI, 2002, p. 56).

Esses dilemas destacam-se nas entrevistas e até nas observações, quando o peso da formação e do saber da experiência vem à tona em falas que postulam descobertas na prática do exercício docente. Ou seja, não descartam a formação e a contribuição 
acadêmica, mas fazem um esforço quase que visceral para adequar esses conhecimentos, nos moldes que foram transmitidos, ao universo do fazer docente.

A teoria com a prática é perfeito, porque às vezes você pega a teoria e pensa: mas como é que eu vou aplicar? Mas quando você pega a experiência: "olha eu fiz de várias maneiras, mas a maneira que deu certo foi essa daqui". Então eu apliquei a teoria e a maneira que teve melhor resultado na sala de aula (PROFESSORA F).

As professoras $\mathrm{C}, \mathrm{K}$ e $\mathrm{Q}$ também concordam com essa perspectiva, elas demonstram diversas contribuições teóricas sobre sua prática, salientam que as leituras e as formações acadêmicas ajudam a repensar o modo de organizar a aula, a elaborar novas atividades, a avaliar seu trabalho pedagógico:

Eu buscava muita teoria, foi daí que eu fiz a Pedagogia, pra ter essa teoria que faltava lá no Magistério, para me dar a base, e depois em cima disso, continuei fazendo, fiz as duas especializações, eu fiz para poder trabalhar melhor. Mas a capacitação, digamos assim, é a minha chave de ouro. Porque quando eu não sei, eu aprendo; quando eu já sei, eu relembro e coloco em prática aquilo que até já havia esquecido (PROFESSORA C).

Enquanto essas docentes se aproximam das perspectivas trazidas por Catani (2002), repensando seu fazer docente a partir de estudos, duas professoras ( $R$ e E) colocam a teoria em um segundo plano de relevância, dizendo que esta apenas complementa a prática pedagógica, mas os saberes docentes baseiam-se, de fato, na experiência adquirida na prática cotidiana:

Não vivo só de teoria não. Acho sim que ela ajuda a aprimorar a prática, mas a prática é muito importante, essa prática que você incorpora ao longo dos anos, ao longo da experiência. Também acredito que no dia a dia a gente use muito do nosso bom senso, pra discernir o que fazer em determinadas situações (PROFESSORA R).

As falas dessas duas participantes vão ao encontro de uma pesquisa de Tardif e Raymond (2000), que mostram que muitos professores veem a experiência como fonte primária do ensinar bem, alegando que o conhecimento oriundo da universidade não traz 
grandes contribuições. Os autores apontam uma falha nos cursos de formação, por muitas vezes não realizarem transformações efetivas nas concepções e crenças dos futuros professores, sendo que esses passam pela universidade, mas continuam a crer nos princípios e vícios que adquiriram por meio de influências familiares, de experiências pessoais ou mesmo na escolarização básica.

Catani (2002), Tardif e Raymond (2000) reconhecem a influência dessas vivências adquiridas ao longo da vida, que foram citadas pela Professora R, julgando-as importantes, entretanto acreditam que as formações iniciais e continuadas devam contribuir para que os docentes reflitam sobre sua história e sua identidade, buscando reconhecer quais elementos constituem essa identidade, quais são as marcas de sua formação que transparecem no desenvolver da prática docente.

Na conjuntura apresentada, nota-se que os elementos advindos da formação inicial e da socialização do exercício profissional vão consolidando aquilo que define-se por identidade, ou seja, uma construção histórica do sujeito, propensa a mudanças. Nesse ínterim, um dos pontos de transformação diz respeito ao universo da dimensão afetiva que condiciona ações e práticas que podem acarretar novos desdobramentos da profissionalidade docente. Os elementos identidade, afetividade e profissionalidade trabalham de maneira justaposta e, em determinado espaço-tempo, pode haver um que esteja em preponderância a outro, contudo, todos tendem a contribuir para a consolidação do ser-professor.

\section{$5 \quad$ Considerações}

A dimensão afetiva se faz presente no bojo das diferentes interações humanas. Vinculando tal dimensão à docência, vimos que esta congrega relações com a ideia de profissionalidade, pois pressupõe que o professor comprometa-se com o outro (obrigação moral); com a comunidade (compromisso com a comunidade) e com a própria formação (competência profissional), aspectos que influenciam sua identidade.

Nesse sentido, o estudo teve como objetivo perceber como a dimensão (sócio) fetiva constitui a identidade dos professores. A prática e o discurso das participantes envolvidas suscitaram pontos possíveis de averiguar a presença dessa dimensão, como, por exemplo, 
na relação que estabelecem consigo mesmas, com o coletivo de docentes, e, principalmente, com os alunos.

No relacionamento com os alunos verificou-se, com as Professoras $C$ e $Q$, que o desenvolvimento da afetividade pode trazer diferentes nuanças à prática pedagógica, na medida em que, a partir dessa afetividade, o professor acaba fortalecendo o trabalho vinculado à formação moral e pessoal dos alunos, baseando sua prática no diálogo, na construção do conhecimento, no exercício de se colocar no lugar do outro.

Com relação ao aspecto afetivo que se estende à noção de compromisso com a comunidade, a Professora E, em especial, ajudou a entender que a afetividade contribui para a construção de um trabalho coletivo entre os docentes, pois auxilia na ruptura do individualismo ao facilitar o relacionamento entre os pares. O compartilhar de ideias e saberes entre os pares, por sua vez, contribui com a constituição da identidade, na medida em que possibilita a consolidação de espaços de formação mútua, onde todos podem assumir a função de formador e formando. Contudo, também reconheceu-se que as políticas públicas afetam o trabalho docente e a organização escolar, sendo que muitas políticas atuais estão aquém do reconhecimento da dimensão afetiva, além de caminharem em prol da competição e do individualismo, reduzindo as chances de que um trabalho efetivamente coletivo seja construído entre os próprios professores e entre professores e comunidade.

Por fim, notou-se que o desenvolvimento da dimensão afetiva pode contribuir para que crenças e concepções pessoais sejam reavaliadas a partir de reflexões e discussões teóricas que permitam relacionar a prática, sempre arraigada por experiências pessoais, à teoria cientificamente elaborada, propiciando um balanço que leve a transformações, pois “Urge [...] (re)encontrar espaços de interacção entre as dimensões pessoais e profissionais, permitindo aos professores apropriar-se dos seu processos de formação e dar-lhes um sentido no quadro das suas histórias de vida" (NÓVOA, 1992, p. 25).

Assim, a conjuntura dos dados leva a crer que a dimensão afetiva pode alavancar atributos profissionais, auxiliando especialmente no desenvolvimento das relações humanas, tornando o trabalho docente mais profundo e/ou consistente. 
Olhando para todos esses elementos relacionados, acabamos por enxergar aspectos que, de certo modo, mostram-se essenciais na luta pela profissionalização da docência, pela reconstrução da identidade dos professores. Aspectos que nos fazem indagar o sentido da educação ao verificar a crise e as inúmeras contradições que a perpassam. Mas que, simultaneamente, nos fazem compreender que a dimensão afetiva pode ser decisiva na construção de um trabalho que se paute pela coletividade e sensibilidade, pela formação pessoal e pela tomada de consciência de si.

\section{Referências}

ALVES-MAZZOTTI, A. J.; GEWANDSZNADJDER, F. O método nas ciências naturais e sociais: pesquisa quantitativa e qualitativa. São Paulo: Pioneira, 2002.

AMADO, J. et al. O lugar da afetividade na Relação Pedagógica. Contributos para a Formação de Professores. Sísifo. Revista de Ciências da Educação, Lisboa, n. 08, p. 75-86, jan./abr. 2009.

ARENDT, H. Entre o passado e o futuro. 6 ed. São Paulo: Editora Perspectiva, 2009.

BARDIN, L. Análise de conteúdo. Lisboa: Edições 70, 1979.

BRASIL. Ministério da Educação. Resolução CNE/CP n. 1/2002, de 18 de fevereiro de 2002. Diário Oficial da União, Brasília, 4 de março de 2002. Seção 1, p. 8.

BRASIL. Ministério da Educação. Parecer CNE/CP n. 9/2001, de 8 de maio de 2001. Documenta, Brasília, n. 476, p. 513-562, 2001.

CATANI, D. B. A Didática como Iniciação: uma alternativa no Processo de Formação de Professores. In: CASTRO, A. D.; CARVALHO, A. M. P. (Orgs.). Ensinar a ensinar: didática para a escola fundamental e média. São Paulo: Pioneira/Thomson Learning, 2002. p. 53-72.

CARVALHO, J. S. F. O declínio do sentido público da educação. Revista Brasileira de Estudos pedagógicos, Brasília, v. 89, n. 223, p. 411-424, set./dez. 2008.

CONTRERAS, J. A Autonomia de professores. São Paulo: Cortez, 2002. 
CUNHA, M. V. O Educador, Sísifo e Odisseu, Diante da Globalização. In: SILVA JR., C. (Org.). VI Circuito PROGRAD: O Profissional formado por seu curso está preparado para as exigências da nova ordem mundial? São Paulo: UNESP, 1996, p. 107 -123.

ENGUITA, M. F. O discurso da Qualidade e a Qualidade do discurso. In.: GENTILI, P. A. A; SILVA, T, T. (Orgs.) Neoliberalismo, Qualidade Total e Educação. Petropólis: Vozes, 1996. p. 95-110.

ENGUITA, M. F. A ambigüidade da docência: entre o profissionalismo e a proletarização. Teoria e Educação, Porto Alegre, v. 4, p. 41-61.1991.

ESTEVE, J. M. A terceira revolução educacional. São Paulo: Moderna, 2004.

ESTEVE, J. M. Mudanças Sociais e Função Docente. In: NÓVOA, A. (Org.) Profissão professor. Porto: Porto Editora, 1992. p. 93-124.

ESTRELA, M. T. Profissão Docente: Dimensões Afectivas e Éticas. Lisboa: Areal Editores, 2010.

FREITAS, L. C. Os Reformadores Empresariais da Educação: da desmoralização do magistério à destruição do sistema público de Educação. Educação e Sociedade, Campinas, v. 33, n. 119, p. 379 404, abr./jun. 2012.

GARCIA, M. M. A.; HYPOLITO, A. M.; VIEIRA, J. S. As identidades docentes como fabricação da docência. Educação e Pesquisa, Campinas, v. 31, n. 01, p. 45-56, jan./mar. 2005.

GENTILI, P. A. A. O discurso da "qualidade" como nova retórica conservadora no campo educacional. In.: GENTILI, P. A. A; SILVA, T, T. (Orgs.) Neoliberalismo, Qualidade Total e Educação. Petropólis: Vozes, 1996. p. 113-177.

GRIGOROWITSCHS, T. O conceito "socialização" caiu em desuso? Uma análise dos processos de socialização na infância com base em Georg Simmel e George H. Mead. Educação e Sociedade, Campinas, vol. 29, n. 102, p. 33-54, jan./mar. 2008.

HOYLE, E. Professionalization and deprofessionalization in education. In: HOYLE, E.; MEGARRY, J. (Eds.). World Yearbook of Education. London: Kogan Page, 1980. p. 42-57.

LÜDKE, M.; BOING, L. A. Caminhos da profissão e da profissionalidade docente. Educação e Sociedade, Campinas, v. 25, n. 89, p. 1150-1180, set./dez. 2004. 
MAUÉS, O. C. Reformas internacionais da Educação e Formação de Professores. Cadernos de Pesquisa, São Paulo, n. 118, p. 89-117, mar. 2003.

NÓVOA, A. Notas sobre a formação (contínua) de professores. In: NÓVOA, A. (Coord.) Os professores e sua formação. Lisboa: Don Quixote, 1992. p. 15-34.

PAPI, S. O. G. Professores: formação e profissionalização. São Paulo: Junqueira e Marin, 2005.

SOUZA NETO, S.; HUNGER, D. A. C. da F. O "Projeto Civilizador Esportivo": a ética em questão. Educação: Teoria e Prática, Rio Claro, vol. 10, n. 18, p. 72-77, jul./dez. 2002.

TARDIF, M.; LESSARD, C. $\mathbf{O}$ trabalho docente: elementos para uma teoria da docência como profissão de interações humanas. Petrópolis: Vozes, 2005.

TARDIF, M.; RAYMOND, D. Saberes, tempo e aprendizagem do trabalho no magistério. Educucação e Sociedade, Campinas, v.21, n.73, p.209-244, dez. 2000.

TOGNETTA, L. R. P.; ASSIS, O. Z. M. de. A construção da solidariedade na escola: as virtudes, a razão e a afetividade. Educação e Pesquisa, São Paulo, v. 32, n. 1, p. 49-66, jan./abr. 2006.

Enviado em Junho/2012

Aprovado em Junho/2013 